\title{
BMJ Open Ten-year trends in traumatic brain injury: a retrospective cohort study of California emergency department and hospital revisits and readmissions
}

\author{
Renee Y Hsia, ${ }^{1,2}$ Amy J Markowitz, ${ }^{3}$ Feng Lin, ${ }^{4}$ Joanna Guo, ${ }^{1}$ Debbie Y Madhok, ${ }^{1}$ \\ Geoffrey T Manley ${ }^{5}$
}

To cite: Hsia RY, Markowitz AJ, Lin F, et al. Ten-year trends in traumatic brain injury: a retrospective cohort study of California emergency department and hospital revisits and readmissions. BMJ Open 2018;8:e022297. doi:10.1136/ bmjopen-2018-022297

- Prepublication history and additional material for this paper are available online. To view these files, please visit the journal online (http://dx.doi. org/10.1136/bmjopen-2018022297).

Received 12 February 2018 Revised 21 September 2018 Accepted 5 October 2018

Check for updates

(C) Author(s) (or their employer(s)) 2018. Re-use permitted under CC BY-NC. No commercial re-use. See rights and permissions. Published by BMJ.

For numbered affiliations see end of article.

Correspondence to

Dr Renee Y Hsia;

renee.hsia@emergency.ucsf.edu

\section{ABSTRACT}

Objective To describe visits and visit rates of adults presenting to emergency departments (EDs) with a diagnosis of traumatic brain injury (TBI). TBI is a major cause of death and disability in the USA; yet, current literature is limited because few studies examine longerterm ED revisits and hospital readmission patterns of TBI patients across a broad spectrum of injury severity, which can help inform potential unmet healthcare needs.

Design We performed a retrospective cohort study. Setting We analysed non-public patient-level data from California's Office of Statewide Health Planning and Development for years 2005 to 2014.

Participants We identified 1.2 million adult patients aged $\geq 18$ years presenting to California EDs and hospitals with an index diagnosis of TBI.

Primary and secondary outcome measures Our main outcomes included revisits, readmissions and mortality over time. We also examined demographics, mechanism and severity of injury and disposition at discharge.

Results We found a $57.7 \%$ increase in the number of TBI ED visits, representing a $40.5 \%$ increase in TBI visit rates over the 10-year period (346-487 per 100000 residents). During this time, there was also a $33.8 \%$ decrease in the proportion of patients admitted to the hospital. Older, publicly insured and black populations had the highest visit rates, and falls were the most common mechanism of injury ( $45.5 \%$ of visits). Of all patients with an index TBI visit, $40.5 \%$ of them had a revisit during the first year, with $46.7 \%$ of them seeking care at a different hospital from their initial hospital or ED visit. Additionally, of revisits within the first year, $13.4 \%$ of them resulted in hospital readmission.

Conclusions The large proportion of patients with TBI who are discharged directly from the ED, along with the high rates of revisits and readmissions, suggest a role for an established system for follow-up, treatment and care of TBI.

\section{INTRODUCTION}

Although traumatic brain injury (TBI) mortality rates have decreased over the last decade, ${ }^{1}$ TBI-related disability has not declined, ${ }^{2}$ and TBI-related emergency
Strengths and limitations of this study

- Our study included all adult patients with a diagnosis of traumatic brain injury (TBI) presenting to the emergency department (ED), including those discharged directly home, thereby capturing a broad spectrum of TBI severity.

- Our study uses a large administrative state database with patient identifiers, which includes all non-federal, general and acute care hospitals in the state, to evaluate longer term outcomes, including revisits, readmissions and longer term mortality.

- Our data did not include patients who experienced a head injury and did not seek care in an ED or hospital, so we may be underestimating the population of patients with mild TBI.

- Our data were limited to the population of California and may not be representative of trends in the entire USA.

department (ED) visits have increased by $70 \%,{ }^{1}$ with a recent report by the Centers for Disease Control and Prevention (CDC) estimating 2.8 million TBI-related $\mathrm{ED}$ visits in $2013 .{ }^{3}$ TBI is bluntly classified as mild, moderate or severe, according to the Glasgow Coma Score (GCS), but this gross characterisation metric fails to capture pathoanatomic distinctions in this multifocal injury and the nuanced and wide-ranging outcomes that are possible. ${ }^{4}$ The persistence of physical, cognitive, behavioural and emotional sequelae of TBI, even mild TBI, is well documented in both short and longer timeframes, ${ }^{5}$ contributing to chronic disability for a significant number of patients. ${ }^{6}$ Currently, TBI is a major cause of disability among adults under age 40 years, ${ }^{7}$ underscoring the importance of better understanding TBI epidemiology, causes and outcomes.

The current evidence base of TBI has shed light on the importance of examining a spectrum of TBI severity, especially mild TBI. ${ }^{8-12}$ 
The literature has shown that patients with TBI of all types of severity, including mild, can experience a range of longer term symptoms and require follow-up care. ${ }^{13-16}$ Some studies have looked at ED revisits and hospital readmissions; however, the majority of these studies use limited sample sizes ${ }^{17-19}$ or have short follow-up periods, ${ }^{1720}$ which may only provide a limited picture of the healthcare need and utilisation after TBI.

To address these gaps, we used California non-public administrative data to answer the question: what are the incidence, demographics and outcomes, including revisits, readmissions and out-of-hospital 1-year mortality of adult TBI patients in California over a 10 -year period? We employed a longitudinal approach as suggested by the International Collaboration on Mild Traumatic Brain Injury $^{21}$ to evaluate these numerous long-term outcomes as the sequelae of TBI can occur long after the traumatic incident or the discharge of the patient. Our study included all adult TBI patients seen in the ED, including those discharged directly home, thereby capturing patients of a broad spectrum of TBI severity.

\section{METHODS}

\section{Study design and data}

We performed a retrospective cohort study of all adult patients with TBI presenting to EDs and hospitals in California from 2005 to 2014. We used non-public patientlevel data from the California Office of Statewide Health Planning and Development (OSHPD), which contain information from all non-federal, general and acute care hospitals in California, including date of admission, patient demographics (age, gender and race/ethnicitydefined as Hispanic, non-Hispanic white, non-Hispanic black and other), comorbidities, diagnostic and procedural information, external cause of injury codes, ${ }^{22}$ disposition and total charges for admissions. Because the data only include hospitalisation charges, our results do not include charges for ED discharges. We obtained vital statistics data to track mortality until 2011, the last year available, and linked the patient-level data with OSHPD utilisation and financial files, which contain hospital-level information such as trauma centre (TC) status.

To calculate TBI visit rates, we obtained California population data, including sex and age from the US Census Bureau, Population Division, and race/ethnicity from the US Census Bureau, American Community Survey (ACS). We calculated visit rates by payer using population by insurance information from the US Census Bureau, Current Population Survey for 2005-2012 and the ACS for 2013-2014. The University of California, San Francisco Institutional Review Board approved this study. Our reporting of protocol conforms to the guidelines for reporting observational studies and is included in the Strengthening the Reporting of Observational Studies in Epidemiology (STROBE) Statement checklist (online supplementary Strobe checklist).

\section{Study population}

Our study population composed of all patients aged $\geq 18$ years presenting to California EDs and hospitals and diagnosed with TBI. Consistent with CDC reporting, ${ }^{3}$ we identified records as TBI-related if they had any of the following International Classification of Diseases, Ninth Revision codes as a primary or secondary diagnosis: 800 . $\mathrm{xx}$, 801.xx, 803.xx, 804.xx, 850.xx - 853.xx, 854.0-1, 905.1-3 and 959.01. We identified patients using record linkage numbers (RLNs) provided in the data and linked all visits with the same RLN to track that patient over time. We defined the first visit for each patient as the index visit. If multiple visits occurred within 1 day of each other, we considered them one event as these could represent ED-to-ED or ED-to-inpatient transfers. Similar to prior studies, ${ }^{23-25}$ we categorised all subsequent visits as revisits and specified readmissions as revisits that resulted in hospitalisation after the index visit.

\section{Patient involvement}

No patients were involved in the study design or in setting the research agenda.

\section{Outcomes and measures}

Our main outcomes included revisits (including ED visits, not only those resulting in admission), readmissions, mean and median inpatient charges during the first year and mortality (ED mortality, in-hospital mortality and out-of-hospital 1-year mortality). We also studied the time from discharge of the initial visit (whether discharged or admitted) to the next revisit and calculated a 'timeto-return' curve. ${ }^{26}$ We collected every patient's Injury Severity Score (ISS) for each visit, which reflects overall trauma severity (not limited to TBI), and grouped them by severity: mild (ISS <9), moderate (ISS 9-15) and severe (ISS $>15) .{ }^{27}{ }^{28}$ We examined outcomes by whether the patient was treated at a TC, where levels I and II are TCs and levels III and IV are non-TCs, consistent with current literature. ${ }^{29} 30$ These classifications are determined by OSHPD, which ranks hospitals from level I-IV based on criteria provided by California local Emergency Medical Services agencies.

\section{Statistical analyses}

To assess TBI index visits, we calculated the numbers and population rates per 100000 by year, both overall and within strata defined by the demographic and clinical characteristics of the sample. To assess secular patterns, we estimated negative binomial models for the numbers of visits, with robust standard errors to account for clustering by hospital, calendar year of admission as a categorical predictor and the log of the population denominator as an offset in the models for rates. In a last step, we evaluated heterogeneity and trend across years using Wald tests, based on the fitted models. To assess the independent associations of age, sex, race/ethnicity, median income, insurance, ISS, mechanism of injury and TC care (as defined above) with numbers of revisits and readmissions 
within 1 year, we also used multivariate negative binomial models, again with robust SEs to account for clustering by hospital. To account for the competing risk of death, these models used the log of the follow-up time as an offset, with appropriately shorter follow-up for patients who died. Finally, to identify risk factors associated with 1-year mortality, both overall and among discharged and admitted patients, we used analogous multivariate logistic models, again with robust SEs to account for clustering by hospital. We conducted all analyses using SAS (V.9.4).

\section{RESULTS}

We identified 1182809 patients aged $\geq 18$ years with an index diagnosis of TBI and described their demographic and clinical characteristics (table 1). During our study period from 2005 to 2014, the proportion of TBI patients grew increasingly older, female, of a racial or ethnic minority, and Medicaid or Medicare insured. The number of index TBI patients grew overall by $57.7 \%$, from 91492 in 2005 to 144269 in 2014 (figure 1), with a $29.5 \%$ increase in the share of index visits due to falls. Approximately $78.9 \%$ of all index TBI patients were discharged from the ED, with the share of discharged patients rising $(72.9 \%$ in 2005 to $82.1 \%$ in 2014$)$ and share of admitted patients $(27.1 \%$ in 2005 to $17.9 \%$ in 2014) and their length of stays (8.2 in 2005 to 6.4 days in 2014) declining. The most common diagnosis for all patients was unspecified head injury $(37.0 \%)$, while the most frequent diagnosis among admitted patients was 'subdural hematoma following injury without mention of open intracranial wound, without loss of consciousness' $(7.7 \%)$. For patients who revisited the ED, the most prevalent diagnosis was hearing loss $(4.1 \%)$ for all revisits and headache $(2.7 \%)$ for readmissions.

When we took into account population growth, the rate of TBI visits rose, from 346 visits per 100000 people in 2005 to 487 visits per 100000 people in 2014, a $40.5 \%$ increase (table 2, figure 1). By 2014, the rate of TBI visits for patients aged $\geq 85$ years was almost five times that of the average, at 2336 visits per 100000 people, a striking $62.3 \%$ increase from the first year of the study period. The growth in TBI rates for females $(59.8 \%)$ was more than double that of males $(25.5 \%)$, and TBI visit rates for Hispanic and black patients both grew faster $(60.2 \%$ for Hispanic and $50.2 \%$ for black) than TBI visit rates for white and other race/ethnicity patients $(42.7 \%$ for white and $45.7 \%$ for other). TBI visit rates rose across all insurance payer groups except for 'other insurance', with the highest increase $(65.6 \%)$ for Medicare patients, and roughly equal growth of $34 \%$ for Medicaid-insured and privately insurance patients. All trends in TBI visit rates were statistically significant at $\mathrm{p}<0.001$.

\section{Trends in dispositions from ED or hospital}

Although the majority of TBI index patients were discharged home from the ED, online supplementary figure 1A, B and online supplementary table 1 illustrate steady increases to alternative sites of healthcare, including skilled nursing facilities (SNFs), intermediate rehabilitation facilities (IRFs), long-term care hospitals (LTCHs), home health services and other healthcare institutions, for patients discharged directly from the ED as well as for those following hospitalisation. While the absolute numbers are small, the proportion of patients discharged from the ED with home health services and hospice more than quintupled $(0.047 \%-0.295 \%, \mathrm{p}<0.001)$ and increased more than 10 -fold $(0.005 \%-0.057 \%, \mathrm{p}<0.001)$ during the study period. Similarly, patients discharged from the hospital on their index visit increasingly used home health services $(6.3 \%-10.5 \%, \mathrm{p}<0.001)$ or an SNF or IRF $(12.5 \%-19.3 \%, \mathrm{p}<0.001)$ for recovery and decreasingly were discharged directly home (58.4\%-49.0\%, $\mathrm{p}<0.001)$.

\section{Revisits, readmissions and inpatient costs}

Of all patients with an index TBI visit, $40.5 \%$ had a revisit during the first year, comprising 1378330 revisits (table 3). Approximately half of revisiting patients had only one revisit $(49.0 \%)$; however, $13.8 \%$ had five or more revisits within the first year, and of all revisits, only $53.3 \%$ occurred at the same hospital as the index visit. Analysis of the 'time-to-return' for the first revisit after the index visit showed that $8.3 \%$ of all first revisits occurred within 1-3 days, with approximately $20 \%$ occurring in the first 2 weeks and about $34 \%$ in the first 2 months (online supplementary figure 2 and online supplementary table 2).

In our analysis of readmissions, $13.4 \%$ of all revisits in the first year resulted in hospital readmission. Slightly less than half $(45.3 \%)$ of these readmissions occurred at the index visit hospital.

When examining factors associated with increased rates of revisits and readmissions, compared with the youngest cohort of patients (18-24 years), non-senior adults (25-64 years) had a $40 \%$ higher revisit rates $(p<0.001)$, and all adults aged $\geq 25$ years had greater readmission rates (relative hazard (RH) 25-44 years: 1.6 ; 45-64 years: 2.6; 65-84 years: $2.4 ; 85+$ years: $2.3, \mathrm{p}<0.001$ ) (table 4 ). The incidence of revisit and readmission rates for black patients was $30 \%$ and $20 \%$ higher, respectively $(p<0.001)$ than those of white patients. All payer categories had a higher incidence of revisit and readmission rates compared with privately insured patients: Medicare patients had $130 \%$ and $140 \%$ higher rates, respectively, and Medicaid patients had $210 \%$ and $150 \%$ higher rates, respectively $($ all $\mathrm{p}<0.001)$. Patients whose mechanism included 'falls' also had higher rates of revisits and readmissions (RH 1.5 and 1.6, respectively, $\mathrm{p}<0.001$ ).

\section{Mortality}

Of all patients with an index TBI visit, 9.8\% died between 2005 and 2010. Of those deaths, 26.8\% occurred during the index hospitalisation, $8.7 \%$ within 30 days, $6.0 \%$ between 31 days and 60 days, $28.6 \%$ within 61 days to a year and the remaining $29.9 \%$ past 1 year after the index visit (table 3 ). Online supplementary table 3 shows the 


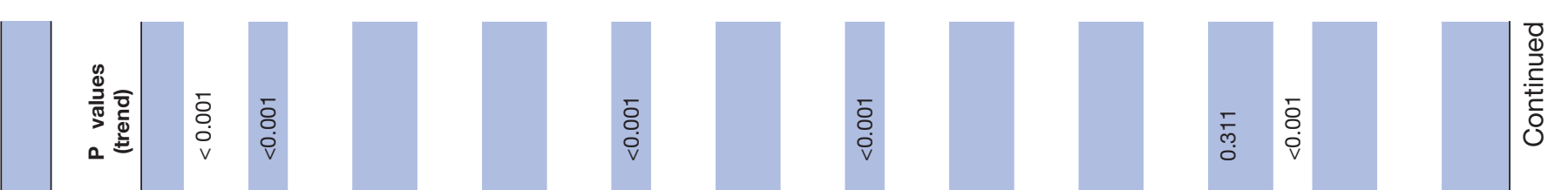

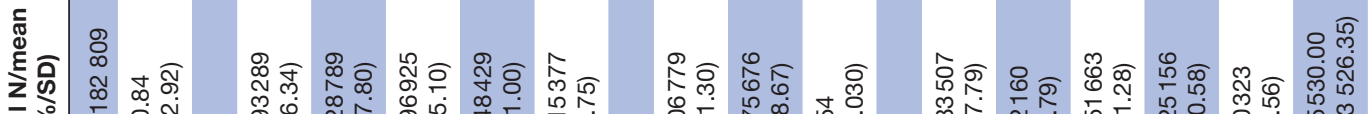
ॠ

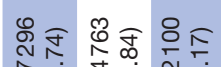
क्ल

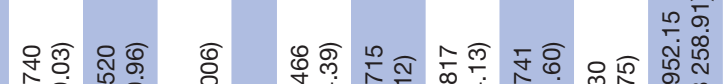

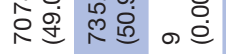

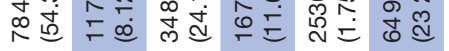

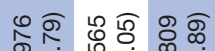

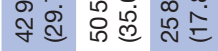

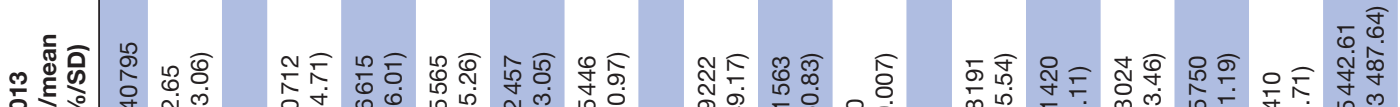

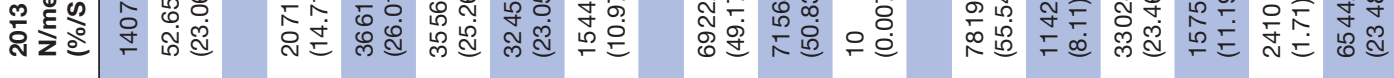

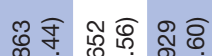

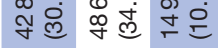

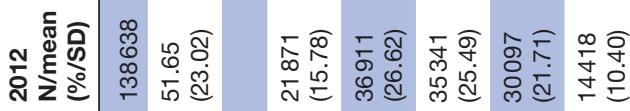

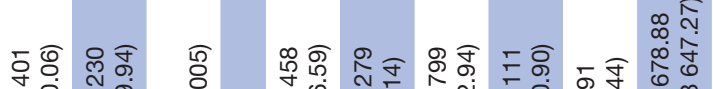

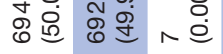

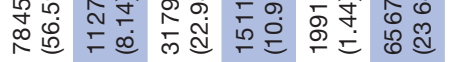

웅

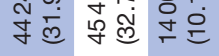

ᄃ

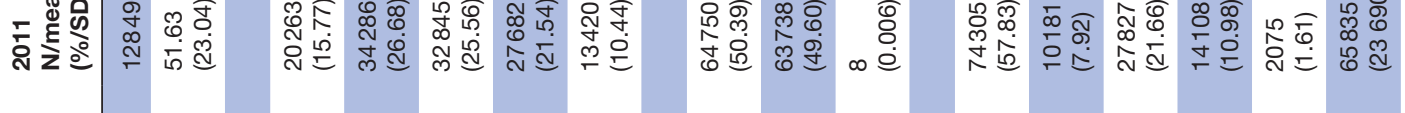

\&

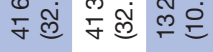

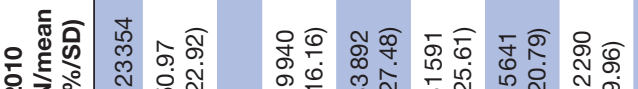

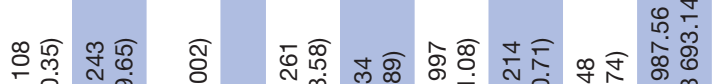

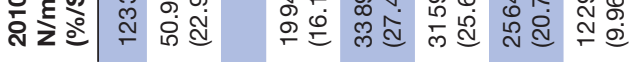

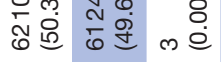

N

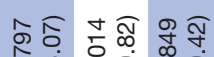
宁遖

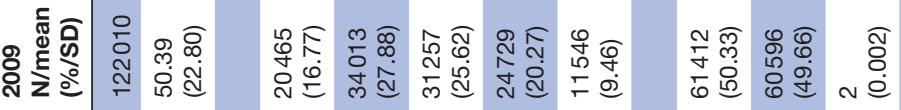

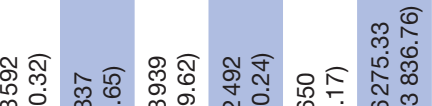

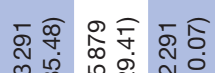

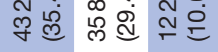

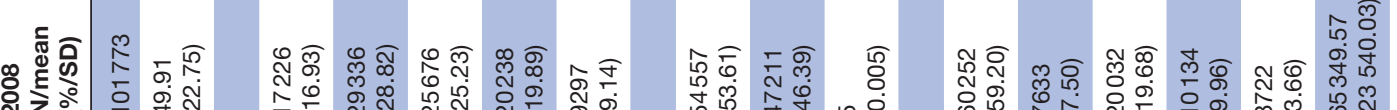

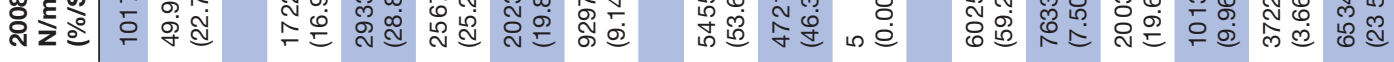

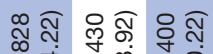

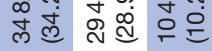

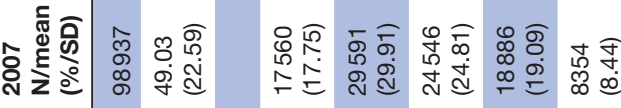

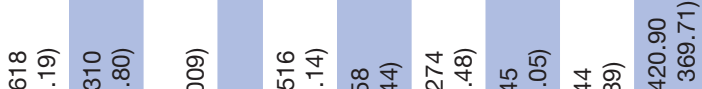

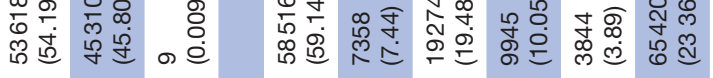

앙 ल्ल

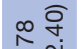

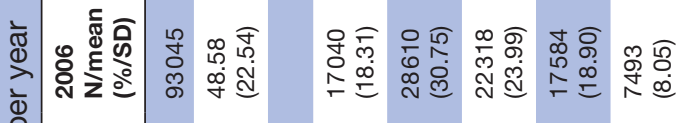

শ্ำ

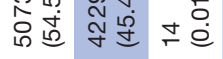

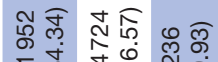

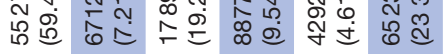
ले स्ट

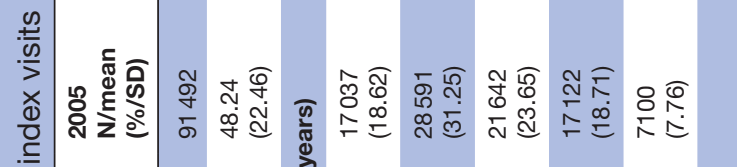

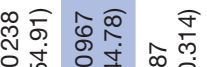
๙ิ 총ำ

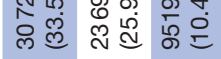
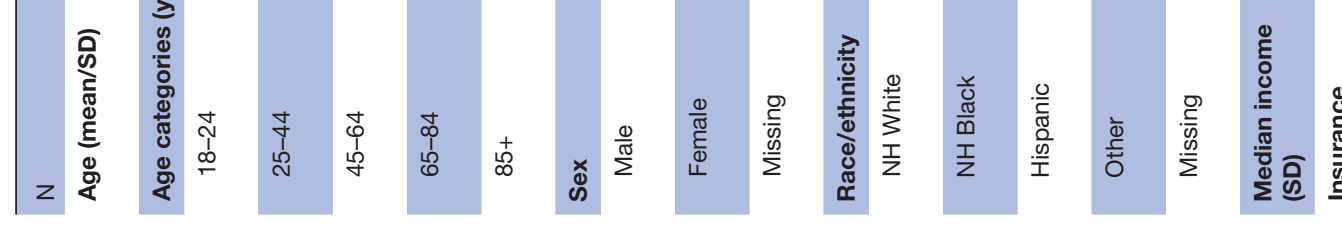

$\frac{\pi}{2}$
$\frac{0}{0}$
$\frac{0}{0}$
$\frac{0}{20}$




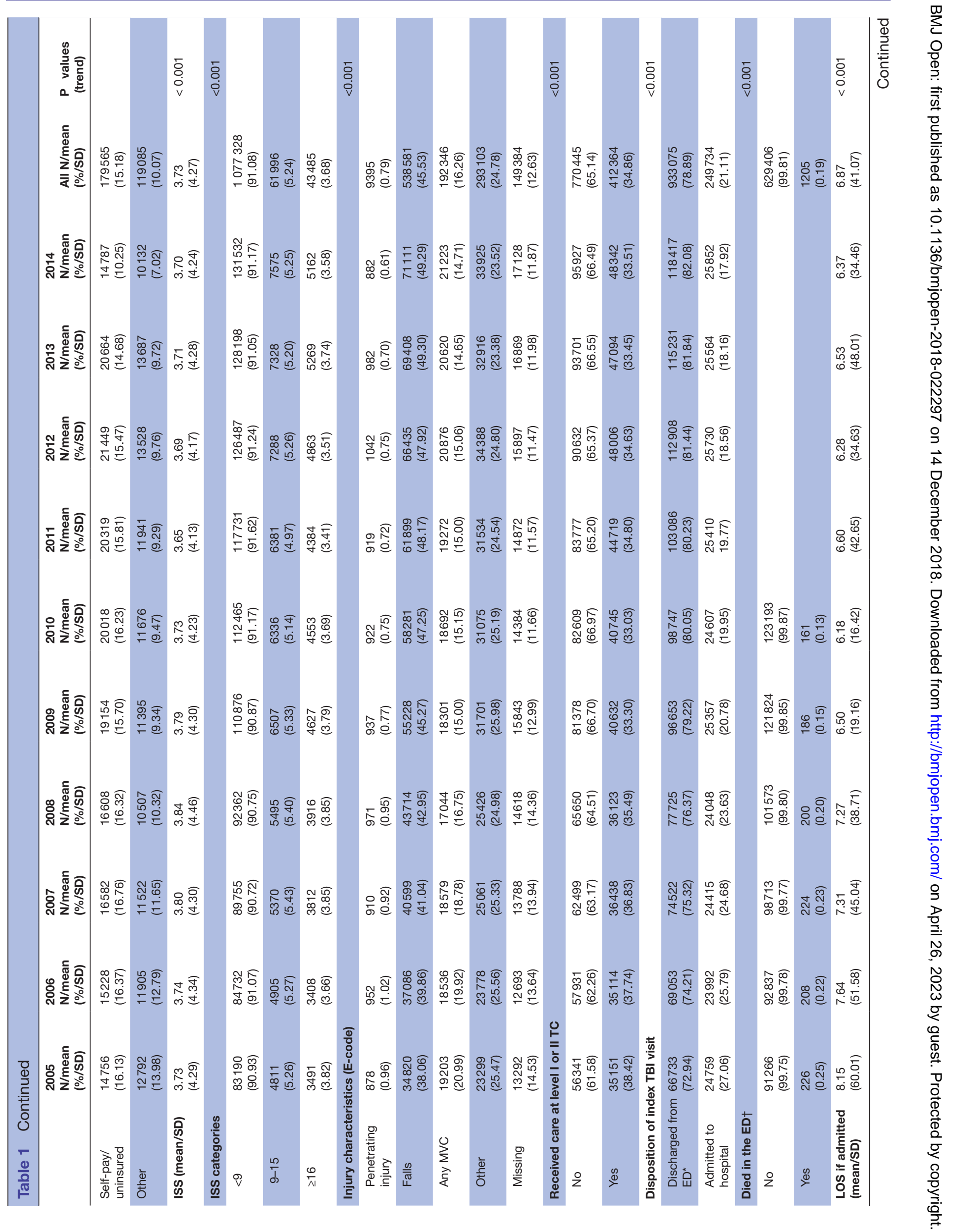


odds of mortality at 1 year among all the patient characteristics examined. Overall, patients who had a higher likelihood of mortality were older, male, white, publicly insured, injured through penetrating injury or falls and treated at a level I or II TC.

Sensitivity analyses of the regressions on death were done by stratifying discharged and admitted patients (online supplementary table 3 ), which showed a smaller range of likelihood of mortality for admitted patients but otherwise similar directions for all variables.

\section{DISCUSSION}

From our study of 1.2 million patients presenting to EDs and hospitals with an index diagnosis of TBI between 2005 and 2014, we found that total index TBI visits grew by $57.7 \%$, and even when adjusted for the population, the per capita rate of index TBI visits rose $40.5 \%$ in the past 10 years alone, with a rate of 487 index TBI visits per 100000 population in 2014. These visit rate results follow the same general trend as in other studies, though our results may be smaller given that we only count index TBI visits. ${ }^{13} 31$ The vast majority of patients $(78.9 \%)$ were discharged directly from the ED, with over $90 \%$ of all patients classified as only 'mildly' injured according to ISS criteria, which are similar to findings from other studies ${ }^{13} 1532$ and highlight the continual need of understanding the sequelae of mild TBI. Some literature has found that a minority of patients with TBI are discharged from the $\mathrm{ED},{ }^{10}{ }^{16}$ but these studies typically contain limited sample sizes suggesting that TBI studies with limited sample sizes may not always be representative of TBI samples from large administrative datasets such as OSHPD and may not capture the broad spectrum of TBI severity.

At the beginning of the study period in 2005, we found a high rate of index TBI visits for patients aged $85+$ years, at 1439 visits per 100000 population aged $85+$ years, which was more than quadruple the average. By 2014 , the rate of index TBI visits for patients aged $85+$ years had increased to 2336 per 100000 , the largest growth in any age group. Consistent with other studies, ${ }^{38} 33$ falls accounted for the preponderance of TBI $(45.5 \%)$ and were the primary driver of the growth in TBI visit rates. The CDC's TBI surveillance summary confirmed that while overall TBI-related deaths have decreased over time, fall-related TBI incidence in the geriatric population is the fastest growing of all demographic segments, and fall-related deaths have increased. ${ }^{3}$ This evidence combined with our findings suggest that more robust fall prevention efforts for elders such as the initiation of fall prevention programmes, including implementing strategies to reduce home hazards, ${ }^{34}$ addressing medication alterations and providing physical training could be beneficial in preventing fall-related TBIs. ${ }^{35}$

When we examined TBI trends by payer, we found that the total number of index TBI visits by Medicaid patients increased $171 \%$ during the study period. This can be partly attributed to the Medicaid expansion ${ }^{36}$ as the rate of TBI 


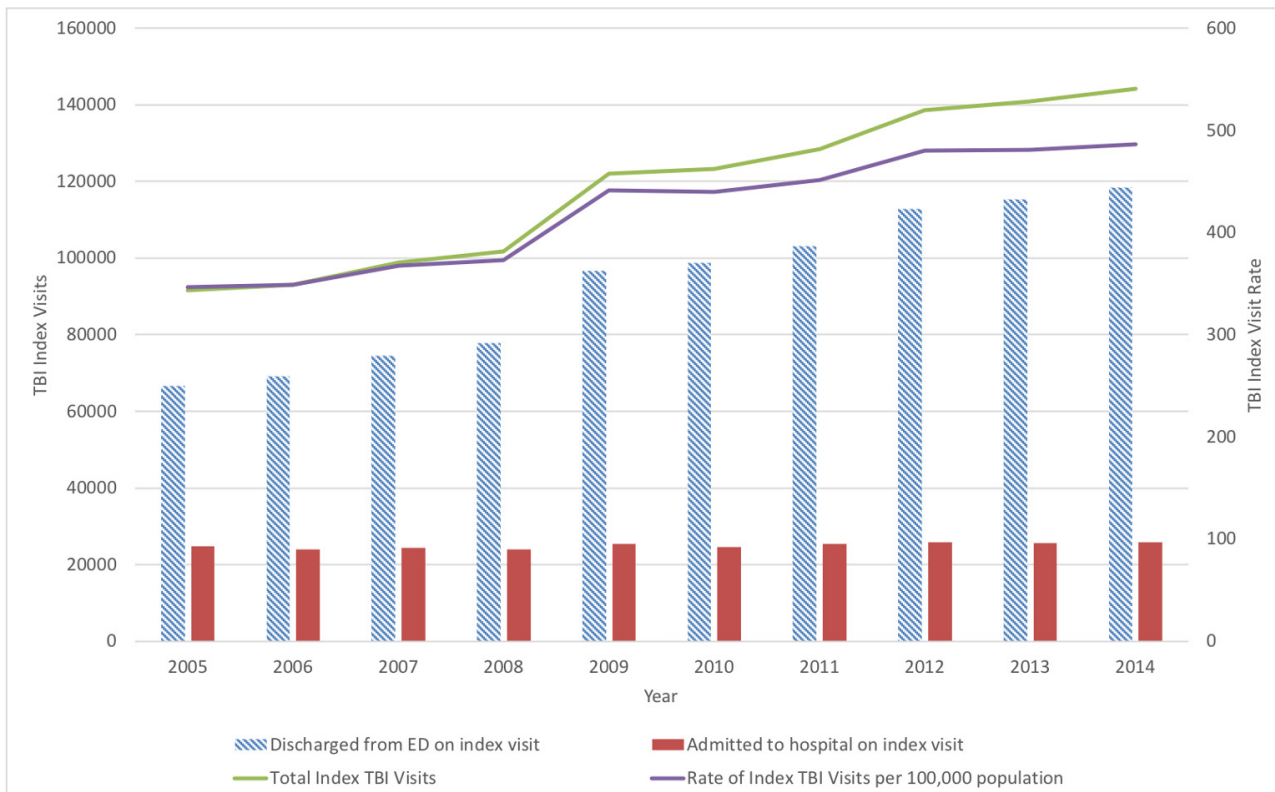

Figure 1 TBI visits overtime in California, 2005-2014. Notes: discharged from ED on index visit includes patients who died in the ED (for more details, please refer to online supplementary table 1). ED, emergency department; TBI, traumatic brain injury.

visits per Medicaid enrollee increased by 20\% from 2013 to 2014. These results can suggest a number of trends, including increased willingness to visit the ED for TBI, greater insurance coverage (ie, Medicaid expansion) for a population that may be more likely to sustain TBI and/ or increased general incidence of TBI. In addition, while our finding of a higher likelihood of mortality for Medicaid-insured patients compared with privately insured patients is consistent with the literature,${ }^{37}$ our finding that Medicaid-insured patients with TBI have a higher likelihood of mortality than Medicare-insured patients with TBI suggests that the Medicaid-insured population may

Table 2 Rate of TBI visits per 100000 persons per year

\begin{tabular}{|c|c|c|c|c|c|c|c|c|c|c|c|}
\hline & 2005 & 2006 & 2007 & 2008 & 2009 & 2010 & 2011 & 2012 & 2013 & 2014 & $\begin{array}{l}\text { P values } \\
\text { (trend) }\end{array}$ \\
\hline Total & 346.27 & 349.13 & 367.60 & 373.03 & 441.00 & 439.73 & 451.65 & 480.47 & 481.35 & 486.56 & $<0.001$ \\
\hline \multicolumn{12}{|l|}{ Age (years) } \\
\hline 18-24 & 462.41 & 460.43 & 469.25 & 451.82 & 527.13 & 507.03 & 509.62 & 544.72 & 515.43 & 530.08 & $<0.001$ \\
\hline $25-44$ & 269.24 & 270.45 & 281.30 & 279.23 & 324.12 & 322.36 & 324.01 & 345.91 & 339.73 & 338.75 & $<0.001$ \\
\hline $45-64$ & 261.39 & 262.62 & 281.95 & 288.26 & 342.51 & 338.63 & 346.20 & 369.62 & 368.29 & 370.17 & $<0.001$ \\
\hline $65-84$ & 511.71 & 523.40 & 553.87 & 578.92 & 690.82 & 698.73 & 732.98 & 760.40 & 786.00 & 790.39 & $<0.001$ \\
\hline $85+$ & 1439.46 & 1460.60 & 1554.52 & 1657.49 & 1974.20 & 2024.33 & 2134.20 & 2219.88 & 2312.78 & 2335.91 & $<0.001$ \\
\hline \multicolumn{12}{|l|}{ Sex } \\
\hline Male & 386.01 & 386.51 & 404.49 & 406.05 & 450.84 & 449.90 & 462.45 & 488.61 & 480.74 & 484.59 & $<0.001$ \\
\hline Female & 305.55 & 312.75 & 331.73 & 340.95 & 431.44 & 429.85 & 441.12 & 472.52 & 481.87 & 488.40 & $<0.001$ \\
\hline \multicolumn{12}{|c|}{ Race/ethnicity } \\
\hline NH White & 439.40 & 431.66 & 457.32 & 471.62 & 580.81 & 578.22 & 594.58 & 627.36 & 624.69 & 627.09 & $<0.001$ \\
\hline NH Black & 461.72 & 418.70 & 453.01 & 469.05 & 574.36 & 592.66 & 615.80 & 678.15 & 677.84 & 693.64 & $<0.001$ \\
\hline Hispanic & 211.70 & 209.23 & 221.32 & 226.01 & 266.24 & 277.84 & 289.65 & 324.93 & 330.59 & 339.14 & $<0.001$ \\
\hline Other & 217.27 & 209.08 & 231.78 & 233.36 & 283.77 & 281.13 & 293.81 & 304.81 & 309.87 & 316.44 & $<0.001$ \\
\hline \multicolumn{12}{|l|}{ Insurance } \\
\hline Private & 205.08 & 206.54 & 216.78 & 225.07 & 300.45 & 275.23 & 284.50 & 286.36 & 290.86 & 275.40 & $<0.001$ \\
\hline Medicaid & 620.52 & 609.82 & 652.61 & 660.14 & 623.55 & 682.91 & 634.17 & 657.36 & 689.26 & 830.14 & $<0.001$ \\
\hline Medicare & 576.30 & 623.83 & 667.63 & 699.84 & 817.63 & 828.07 & 874.96 & 941.79 & 958.39 & 954.24 & $<0.001$ \\
\hline Uninsured & 283.04 & 287.66 & 307.30 & 293.70 & 303.45 & 321.59 & 316.64 & 363.78 & 354.63 & 346.30 & $<0.001$ \\
\hline Other & 1561.69 & 1670.26 & 1742.13 & 1445.67 & 1323.74 & 1221.92 & 1317.12 & 1470.57 & 1278.08 & 920.25 & $<0.001$ \\
\hline
\end{tabular}

$\mathrm{NH}$, non-Hispanic; TBI, traumatic brain injury. 
Table 3 Outcomes of patients with TBI: all-cause revisits and readmissions

\begin{tabular}{|c|c|c|}
\hline & $\mathbf{N}$ & $\%$ \\
\hline \multicolumn{3}{|c|}{ Hospital revisits (any ED visit or hospital readmission) } \\
\hline Total revisits & 5572379 & \\
\hline Revisits within 1 year of index visit & 1378330 & 24.74 \\
\hline $\begin{array}{l}\text { Total patients with } \geq 1 \text { revisit within } 1 \text { year } \\
\text { of index visit }\end{array}$ & 479225 & 40.52 \\
\hline \multicolumn{3}{|c|}{ Patients by number of revisits within 1 year of index visit } \\
\hline 1 revisit & 234583 & 48.95 \\
\hline 2 revisits & 99931 & 20.85 \\
\hline 3 revisits & 50297 & 10.50 \\
\hline 4 revisits & 28379 & 5.92 \\
\hline $5-9$ revisits & 45976 & 9.59 \\
\hline$\geq 10$ revisits & 20059 & 4.19 \\
\hline \multicolumn{3}{|l|}{ Revisited the same hospital as index visit? } \\
\hline Yes & 734777 & 53.31 \\
\hline No & 643553 & 46.69 \\
\hline \multicolumn{3}{|l|}{ Hospital readmissions } \\
\hline Total readmissions & 1484359 & \\
\hline Readmissions within 1 year of index visit & 185061 & 12.47 \\
\hline $\begin{array}{l}\text { Total patients with } \geq 1 \text { readmission within } \\
1 \text { year of index visit }\end{array}$ & 89957 & 7.61 \\
\hline \multicolumn{3}{|c|}{ Patients by number of readmissions within 1 year of index visit } \\
\hline 1 readmission & 49225 & 54.72 \\
\hline 2 readmissions & 19360 & 21.52 \\
\hline 3 readmissions & 9402 & 10.45 \\
\hline 5 readmissions & 4902 & 5.45 \\
\hline 5-9 readmissions & 6223 & 6.92 \\
\hline$\geq 10$ readmissions & 845 & 0.94 \\
\hline \multicolumn{3}{|c|}{ Readmitted at the same hospital as index visit? } \\
\hline Yes & 83755 & 45.26 \\
\hline No & 101306 & 54.74 \\
\hline \multicolumn{3}{|l|}{ Mortality ${ }^{\star}$} \\
\hline Total deaths from 2005 to 2010 & 61627 & 9.77 \\
\hline \multicolumn{3}{|l|}{ Died within...? } \\
\hline Index hospitalisation & 16511 & 2.62 \\
\hline 30 days after index visit & 5354 & 0.85 \\
\hline 31-60 days after index visit & 3702 & 0.59 \\
\hline 61 days -1 year after index visit & 17643 & 2.80 \\
\hline
\end{tabular}

Percentages may not sum to $100 \%$ due to rounding error. *Includes only patients with vital statistics data of 2011, most current from the Office of Statewide Health Planning and Development.

ED, emergency department.

be receiving inadequate follow-up care such as rehabilitation programmes or have greater concomitant life-threatening injuries and comorbidities. ${ }^{37} 38$

Our findings on TBI trends by race/ethnicity showed that although the number of visits by Hispanic patients more than doubled, the TBI visit rate for Hispanics was only half as large as the visit rates for white and black patients. This result combined with our findings that minority race/ethnic groups were associated with lower rates of revisit and readmission and lower likelihood of mortality, which are consistent with another study, ${ }^{39}$ likely point to an ageing white population. It is possible that a large share of the black population may also be ageing into the elderly category (age 65 years and over), the age group with the highest TBI visit rate and associated with higher rates of revisit and readmission. However, in conjunction with our findings of a slightly reduced likelihood of mortality for black patients, consistent with the literature, ${ }^{39}$ the results more likely suggest a combination of factors aside from ageing, such as greater incidence of assault or violence, ${ }^{40}$ greater likelihood of being a bluecollar worker ${ }^{41}$ or reduced access or usage of follow-up care. ${ }^{37}$ These findings point to potential unobserved consequences of TBI for black patients, which may affect long-term health and have indirect socioeconomic consequences.

Our study tracked ED and hospital revisits and readmissions of all patients with TBI following any ED visit during the study period using a large administrative state database. Because $40.5 \%$ of patients had at least one revisit within the first year, current patient care and discharge practices, including patient education regarding potential sequelae of TBI at the index visit may not be adequate. ${ }^{42}$ Overall, the high frequency of ED revisits and subsequent hospitalisations within the first year provides evidence of delayed symptoms and sequelae experienced by TBI patients, ${ }^{43}$ contributing to the difficulty of providing adequate patient care at the index visit. Our findings, along with increasing evidence from other studies, ${ }^{9} 424445$ suggest that many mild TBI cases that do not require hospitalisation should likely not be considered uncomplicated, one-time events and may require an established system of multidisciplinary follow-up care. ${ }^{14}$ Because we found that only $13.4 \%$ of revisits resulted in readmission, organising a system of outpatient TBI care to appropriately treat this high proportion of returning patients, particularly those revisiting within 3 days following discharge, could be of great health and economic value. ${ }^{46}$ In particular, our findings that approximately half of all revisits and readmissions did not occur at the hospital of the index visit serve as potential evidence of poor TBI-specific follow-up care and the need for more comprehensive discharge instructions. While there are some reports of postacute rehabilitation for TBI-diagnosed patients and some models of community-integrated rehabilitation, many of these are focused on military personnel and are not widely available for civilian populations. ${ }^{47}$ Our findings suggest that implementation of established systems of community-based TBI-specific care could potentially benefit patients and decrease healthcare utilisation.

Our study marks a starting point to understand the changing characteristics of patients with TBI, including trends in revisits and readmissions, which can help inform 
Table 4 Negative binomial regression for revisits and readmissions

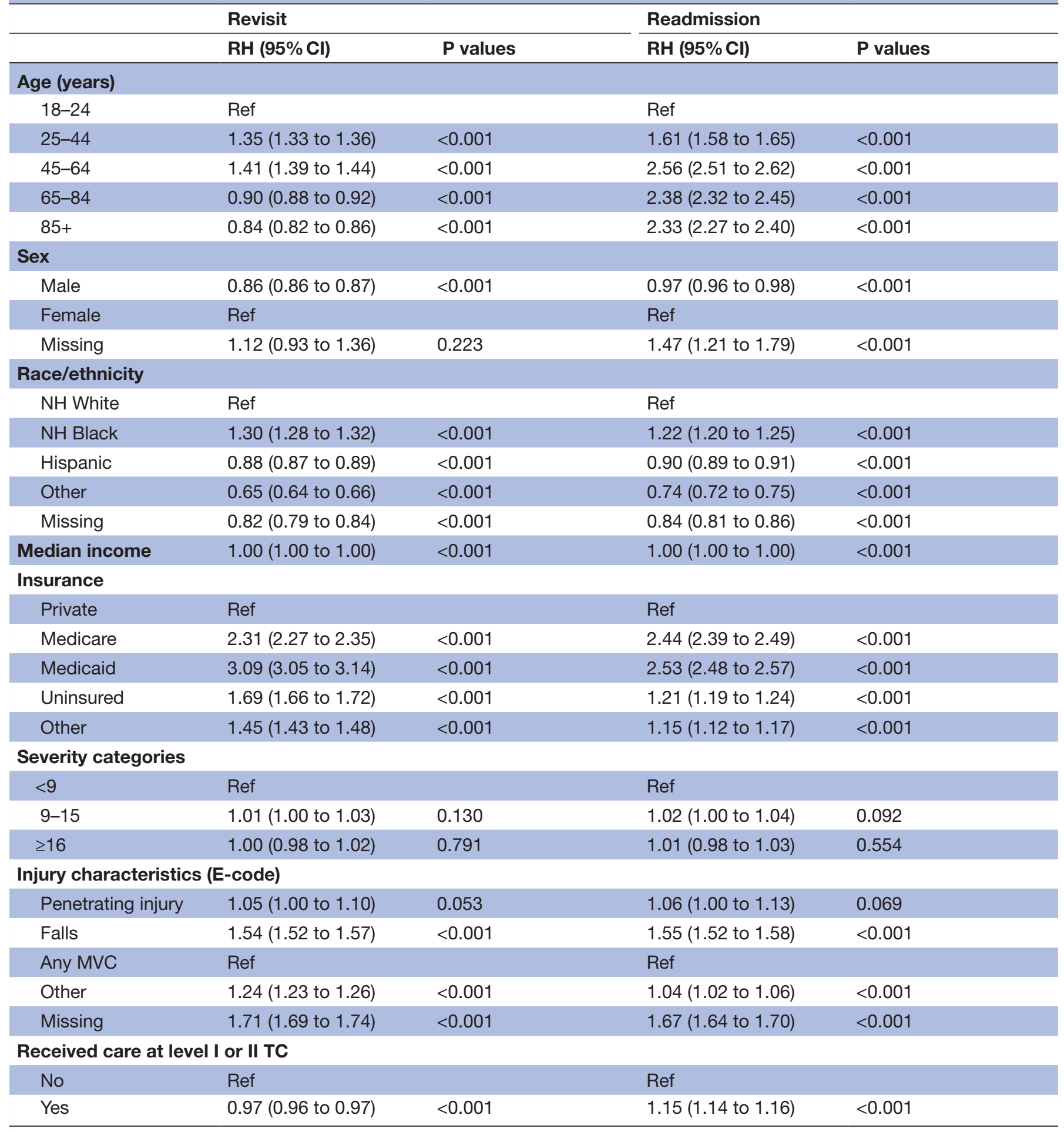

MVC, motor vehicle collision; $\mathrm{NH}$, non-Hispanic; $\mathrm{RH}$, relative hazard; $\mathrm{TC}$, trauma centre.

strategies to improve our ability to assess and provide quality care for TBI-diagnosed patients. Future studies will further elucidate the nature of revisits and readmissions to provide better insight for both ED and inpatient providers.

\section{Limitations}

Our study includes several limitations. First, patients with TBI frequently suffer concomitant injuries, which make it difficult to evaluate only patients with isolated head trauma and to fully assess whether outcomes and revisits resulted from brain injury, other traumatic injury or comorbidities. Second, we based our inclusion criteria on prior work, ${ }^{3}$ and as with any coded diagnosis data, codes may not always precisely reflect the nature of the visit and could potentially overestimate the number of patients diagnosed with TBI. Consequently, some of our findings should be taken in this context; for example, the higher mortality rate in TCs. 
While we did adjust for trauma severity using standard risk adjustment in trauma literature,${ }^{48-50}$ it is clear that administrative data, no matter how complete, can never capture the full picture of a patient's precise condition. Since patients with more severe trauma are more likely to be taken to a TC, the finding of a higher mortality rate at TCs is unsurprising. Third, our data do not include patients who experienced a head injury and did not seek care in an ED or hospital, but rather potentially sought care from their primary care doctors or elsewhere (or perhaps died before they were taken to a hospital), and so we may be underestimating the population of patients with TBI. Fourth, we did not have clinical information such as patient neurological status or imaging results, and while we did classify the general severity of overall trauma with ISS metrics, ${ }^{27} 28$ we could not identify whether the head injury itself was classified as mild, moderate or severe according to the commonly used GCS. Finally, our data set is limited to the population of the state of California and may not be representative of trends in the entire USA. However, given that California represents 12\% of the US population and has a broad spectrum of socioeconomic and racial/ethnic diversity, these findings may be informative for others interested in trends in TBI care and management.

Overall, as most TBI studies focus on hospitalised patients, or those who at least received a head CT scan, ${ }^{51}$ our study distinctively uses a larger universe of patients diagnosed with TBI who may not have even obtained an initial head CT. Our study greatly expands the evidence derived from previous studies as we did not restrict our sample to a certain subgroup of a specific age ${ }^{52}{ }^{53}$ cause or severity of injury or region, ${ }^{54}$ and instead used all California adult patient hospital TBI cases, including those discharged directly from the ED.

\section{CONCLUSIONS}

We find an increasing number of patients presenting to EDs and hospitals with a diagnosis of TBI over the past decade, especially among the elderly, with falls being the predominant mechanism of injury. The highest TBI visit rates were among the elderly, publicly insured and black populations. The proportion of patients discharged directly from the ED has steadily grown over time, with an increasing number of discharged patients (both from the ED and the hospital) discharged to alternative forms of healthcare, such as SNF, IRF, LTCH and home health services. Importantly, there are substantial revisits and readmissions for patients with TBI index visits, with greater incidence of revisit and readmission rates among black, publicly insured and fall-injured patients. These findings suggest that understanding the entire universe of patients across the severity spectrum of TBI-especially those discharged without follow-up care-will be critically important in TBI prevention efforts as well in the design of improvements to follow-up, care and rehabilitation of these patients.
Author affiliations

${ }^{1}$ Department of Emergency Medicine, University of California, San Francisco, San Francisco, California, USA

${ }^{2}$ Philip R. Lee Institute for Health Policy Studies, University of California, San Francisco, San Francisco, California, USA

${ }^{3}$ Brain and Spinal Injury Center (BASIC), University of California, San Francisco, San Francisco, California, USA

${ }^{4}$ Department of Epidemiology and Biostatistics, University of California, San Francisco, San Francisco, California, USA

${ }^{5}$ Department of Neurological Surgery, University of California, San Francisco, San Francisco, California, USA

Acknowledgements The authors would like to thank the California Office of Statewide Health Planning and Development for providing the datasets used in this project; and Seth Seabury, PhD, for comments on the draft of this article.

Contributors RYH, AJM and GTM contributed to the conception and design of the study. RYH, FL and JG contributed to the analysis and interpretation of the data. RYH acquired the data. GTM acquired the funding. DYM, RYH and JG drafted the manuscript. All authors critically revised the manuscript for important intellectual content and approved the manuscript.

Funding This study was supported in part by NIH 1U01 NS086090-01 (GTM), One Mind (GTM and AJM) and a gift from the Fisher Family.

Competing interests GTM discloses grants from the US Department of Defense - TBI Endpoints Development Initiative (Grant \#W81XWH-14-2-0176), TRACK-TBI Precision Medicine (Grant \#TBD) and TRACK-TBI NETWORK (Grant \# W81XWH-15-9-0001); National Institutes of Health - National Institute of Neurological Disorders and Stroke - TRACK-TBI (\#U01NS086090); and the National Football League (NFL) Scientific Advisory Board - TRACK-TBI LONGITUDINAL. US Department of Energy supports GTM for a precision medicine collaboration. One Mind has provided funding for TRACK-TBI patients stipends and support to clinical sites. He has received an unrestricted gift from the NFL to the University of California, San Francisco Foundation to support research efforts of the TRACKTBI NETWORK. GTM has also received funding from NeuroTrauma Sciences LLC to support TRACK-TBI data curation efforts. Additionally, Abbott Laboratories has provided funding for add-in TRACK-TBI clinical studies. AJM receives funding from the Department of Defense TRACK-TBI NETWORK (Grant \# W81XWH-15-9-0001) and salary support from the US Department of Energy precision medicine collaboration and One Mind.

Patient consent Not required.

Ethics approval This study used deidentified, precollected data and was therefore deemed exempt from review by the University of California, San Francisco Institutional Review Board.

Provenance and peer review Not commissioned; externally peer reviewed.

Data sharing statement The data are available through the California Office of Statewide Health Planning and Development.

Open access This is an open access article distributed in accordance with the Creative Commons Attribution Non Commercial (CC BY-NC 4.0) license, which permits others to distribute, remix, adapt, build upon this work non-commercially, and license their derivative works on different terms, provided the original work is properly cited, appropriate credit is given, any changes made indicated, and the use is non-commercial. See: http://creativecommons.org/licenses/by-nc/4.0/.

\section{REFERENCES}

1. Centers for Disease Control and Prevention. Rates of TBI-related emergency department visits, hospitalizations, and deaths - United States, 2001-2010. Atlanta, GA: U.S. Department of Health \& Human Services, 2016. https://www.cdc.gov/traumaticbraininjury/data/rates. html.

2. Shukla D, Devi BI, Agrawal A. Outcome measures for traumatic brain injury. Clin Neurol Neurosurg 2011;113:435-41.

3. Taylor CA, Bell JM, Breiding MJ, et al. Traumatic brain injury-related emergency department visits, hospitalizations, and Deaths - United States, 2007 and 2013. MMWR Surveill Summ 2017;66:1-16.

4. Manley GT, Maas Al. Traumatic brain injury: an international knowledge-based approach. JAMA 2013;310:473-4.

5. Kay T, Harrington DE, Adams R, et al. Definition of mild traumatic brain injury. J Head Trauma Rehabil 1993;8:86-7. 
6. Thornhill S, Teasdale GM, Murray GD, et al. Disability in young people and adults one year after head injury: prospective cohort study. BMJ 2000;320:1631-5.

7. Fleminger S, Ponsford J. Long term outcome after traumatic brain injury. BMJ 2005;331:1419-20.

8. Cancelliere C, Coronado VG, Taylor CA, et al. Epidemiology of isolated versus nonisolated mild traumatic brain injury treated in emergency departments in the United States, 2006-2012 sociodemographic characteristics. J Head Trauma Rehabil 2017;32:E37-E46.

9. Dams-O'Connor K, Spielman L, Singh A, et al. The impact of previous traumatic brain injury on health and functioning: a TRACKTBI study. J Neurotrauma 2013;30:2014-20.

10. de Koning ME, Scheenen ME, van der Horn HJ, et al. Nonhospitalized patients with mild traumatic brain injury: the forgotten minority. J Neurotrauma 2017;34:257-61.

11. Albrecht JS, Hirshon JM, McCunn M, et al. Increased rates of mild traumatic brain injury among older adults in US emergency departments, 2009-2010. J Head Trauma Rehabil 2016;31:E1-E7.

12. van der Naalt J, Timmerman ME, de Koning ME, et al. Early predictors of outcome after mild traumatic brain injury (UPFRONT): an observational cohort study. Lancet Neurol 2017;16:532-40.

13. Scholten AC, Haagsma JA, Andriessen TM, et al. Health-related quality of life after mild, moderate and severe traumatic brain injury: patterns and predictors of suboptimal functioning during the first year after injury. Injury 2015;46:616-24.

14. Seabury SA, Gaudette É, Goldman DP, et al. Assessment of followup care after emergency department presentation for mild traumatic brain injury and concussion. JAMA Netw Open 2018;1:e180210.

15. Yue JK, Winkler EA, Sharma S, et al. Temporal profile of care following mild traumatic brain injury: predictors of hospital admission, follow-up referral and six-month outcome. Brain Inj 2017;31:1820-9.

16. de Koning ME, Scheenen ME, van der Horn HJ, et al. Outpatient follow-up after mild traumatic brain injury: Results of the UPFRONTstudy. Brain Inj 2017;31:1102-8.

17. Ganti L, Conroy LM, Bodhit A, et al. Understanding why patients return to the emergency department after mild traumatic brain injury within 72 hours. West J Emerg Med 2015;16:481-5.

18. Southerland LT, Stephens JA, Robinson S, et al. Head trauma from falling increases subsequent emergency department visits more than other fall-related injuries in older adults. J Am Geriatr Soc 2016;64:870-4.

19. Nakase-Richardson R, Tran J, Cifu D, et al. Do rehospitalization rates differ among injury severity levels in the NIDRR Traumatic Brain Injury Model Systems program? Arch Phys Med Rehabil 2013;94:1884-90.

20. Canner JK, Giuliano K, Gani F, et al. Thirty-day re-admission after traumatic brain injury: Results from MarketScan ${ }^{\circledR}$. Brain Inj 2016;30:1570-5.

21. Kristman VL, Borg J, Godbolt AK, et al. Methodological issues and research recommendations for prognosis after mild traumatic brain injury: results of the International Collaboration on Mild Traumatic Brain Injury Prognosis. Arch Phys Med Rehabil 2014;95:S265-S277.

22. Centers for Disease Control and Prevention. WISQARS Cost of Injury Reports Help Menu: Section 3.2 Mechanism (Cause) of Injury. Atlanta, GA: U.S. Department of Health \& Human Services, 2014. https://www.cdc.gov/injury/wisqars/cost_help/mechanism_injury. html.

23. Sabbatini AK, Kocher KE, Basu A, et al. In-hospital outcomes and costs among patients hospitalized during a return visit to the emergency department. JAMA 2016;315:663-71.

24. Vashi AA, Fox JP, Carr BG, et al. Use of hospital-based acute care among patients recently discharged from the hospital. JAMA 2013;309:364-71.

25. Gabayan GZ, Asch SM, Hsia RY, et al. Factors associated with short-term bounce-back admissions after emergency department discharge. Ann Emerg Med 2013;62:136-44.

26. Rising KL, Victor TW, Hollander JE, et al. Patient returns to the emergency department: the time-to-return curve. Acad Emerg Med 2014;21:864-71.

27. Bolorunduro OB, Villegas $C$, Oyetunji TA, et al. Validating the Injury Severity Score (ISS) in different populations: ISS predicts mortality better among Hispanics and females. J Surg Res 2011;166:40-4.

28. Geiger AA, deRoon-Cassini T, Brasel KJ. Considering the patient's perspective in the injury severity score. J Surg Res 2011;170:133-8.

29. Hsia RY, Wang E, Saynina O, et al. Factors associated with trauma center use for elderly patients with trauma: a statewide analysis, 1999-2008. Arch Surg 2011;146:585-92.
30. Newgard CD, Staudenmayer K, Hsia RY, et al. The cost of overtriage: more than one-third of low-risk injured patients were taken to major trauma centers. Health Aff 2013;32:1591-9.

31. Marin JR, Weaver MD, Yealy DM, et al. Trends in visits for traumatic brain injury to emergency departments in the United States. JAMA 2014;311:1917-9.

32. Kerr ZY, Harmon KJ, Marshall SW, et al. The epidemiology of traumatic brain injuries treated in emergency departments in North Carolina, 2010-2011. N C Med J 2014;75:8-14.

33. Lagbas C, Bazargan-Hejazi S, Shaheen M, et al. Traumatic brain injury related hospitalization and mortality in California. Biomed Res Int 2013;2013:1-9.

34. Pfortmueller CA, Lindner G, Exadaktylos AK. Reducing fall risk in the elderly: risk factors and fall prevention, a systematic review. Minerva Med 2014:105:275-81.

35. Karlsson MK, Vonschewelov T, Karlsson C, et al. Prevention of falls in the elderly: a review. Scand J Public Health 2013;41:442-54.

36. Nikpay S, Freedman S, Levy $\mathrm{H}$, et al. Effect of the affordable care act medicaid expansion on emergency department visits: evidence from state-level emergency department databases. Ann Emerg Med 2017:70:215-25.

37. Schiraldi M, Patil CG, Mukherjee D, et al. Effect of insurance and racial disparities on outcomes in traumatic brain injury. J Neurol Surg A Cent Eur Neurosurg 2015;76:224-32.

38. Wei W, Sambamoorthi U, Crystal S, et al. Mental illness, traumatic brain injury, and medicaid expenditures. Arch Phys Med Rehabil 2005;86:905-11.

39. McQuistion K, Zens T, Jung HS, et al. Insurance status and race affect treatment and outcome of traumatic brain injury. J Surg Res 2016;205:261-71.

40. Linton KF, Kim BJ. Traumatic brain injury as a result of violence in Native American and Black communities spanning from childhood to older adulthood. Brain Inj 2014;28:1076-81.

41. The Henry J. Kaiser Family Foundation. Health coverage by race and ethnicity: the potential impact of the Affordable Care Act. 2013 http:// www.kff.org/disparities-policy/issue-brief/health-coverage-by-raceand-ethnicity-the-potential-impact-of-the-affordable-care-act/.

42. Dikmen S, Machamer J, Temkin N. Mild traumatic brain injury: longitudinal study of cognition, functional status, and post-traumatic symptoms. J Neurotrauma 2017;34:1524-30.

43. Bazarian JJ, Cernak I, Noble-Haeusslein L, et al. Long-term neurologic outcomes after traumatic brain injury. J Head Trauma Rehabil 2009;24:439-51.

44. Haarbauer-Krupa J, Taylor CA, Yue JK, et al. Screening for posttraumatic stress disorder in a civilian emergency department population with traumatic brain injury. J Neurotrauma 2017;34:50-8.

45. Palacios EM, Yuh EL, Chang YS, et al. Resting-state functional connectivity alterations associated with six-month outcomes in mild traumatic brain injury. J Neurotrauma 2017;34:1546-57.

46. Minen M, Shome A, Femia R, et al. Emergency Department concussion revisits: Chart review of the evaluation and discharge plans of post-traumatic headache patients. Am J Emerg Med 2017;35:365-7.

47. Trudel TM, Nidiffer FD, Barth JT. Community-integrated brain injury rehabilitation: Treatment models and challenges for civilian, military, and veteran populations. J Rehabil Res Dev 2007;44:1007-16.

48. Hsia RY, Srebotnjak T, Maselli J, et al. The association of trauma center closures with increased inpatient mortality for injured patients. J Trauma Acute Care Surg 2014;76:1048-54.

49. Staudenmayer KL, Weiser TG, Maggio PM, et al. Trauma center care is associated with reduced readmissions after injury. J Trauma Acute Care Surg 2016;80:412-8.

50. Staudenmayer KL, Hsia RY, Mann NC, et al. Triage of elderly trauma patients: a population-based perspective. J Am Coll Surg 2013;217:569-76.

51. Yue JK, Vassar MJ, Lingsma HF, et al. Transforming research and clinical knowledge in traumatic brain injury pilot: multicenter implementation of the common data elements for traumatic brain injury. J Neurotrauma 2013;30:1831-44.

52. Emery CA, Barlow KM, Brooks BL, et al. A systematic review of psychiatric, psychological, and behavioural outcomes following mild traumatic brain injury in children and adolescents. Can J Psychiatry 2016;61:259-69.

53. Kania K, Shaikh KA, White IK, et al. Follow-up issues in children with mild traumatic brain injuries. J Neurosurg Pediatr 2016;18:224-30.

54. Brown AW, Leibson CL, Malec JF, et al. Long-term survival after traumatic brain injury: a population-based analysis. NeuroRehabilitation 2004;19:37-43. 